\title{
Relative Risk and Odds Ratio of Risk Factors Associated with Digestive Diseases in Ganjam Goats of Odisha
}

\author{
Dillip Kumar Karna ${ }^{1 *}$, Aditya Prasad Acharya ${ }^{2}$, Bhabesh Chandra Das ${ }^{3}$, \\ Gangadhar Nayak ${ }^{1}$ and M.R. Dibyadarshini ${ }^{1}$ \\ ${ }^{1}$ Department of Animal Breeding and Genetics, College of Veterinary Science and Animal Husbandry, Orissa University of \\ Agriculture and Technology, Odisha, INDIA \\ ${ }^{2}$ Department of Veterinary Pathology, College of Veterinary Science and Animal Husbandry, OUAT, Odisha, INDIA \\ ${ }^{3}$ Department of Veterinary \& Animal Husbandry Extension, College of Veterinary Science and Animal Husbandry, \\ OUAT, Odisha, INDIA \\ *Corresponding author: DK Karna; E-mail: dkarna@gmail.com
}

Received: 27 May, 2021

Revised: 10 June, 2021

Accepted: 15 June, 2021

\begin{abstract}
A two-year study on the morbidity and mortality in Ganjam goats of Odisha associated with digestive diseases was carried out in Ganjam district of Odisha and the effects of year, season, sex, age group and rearing management on morbidity and mortality rates due to these diseases were examined using suitable statistical techniques. Morbidity and mortality data of 5845 Ganjam goats of 71 goat keepers and 5205 Ganjam goats of 104 goat keepers from four clusters of Ganjam district were recorded from April 2018 to March 2019 and April 2019 to March 2020, respectively, each year divided into three seasons: summer (MarchJune), rainy (July-October) and winter (November-February). These goats reared under both range system and semi-intensive rearing system were divided into three groups: kids (0-3 months), young stocks (3-12 months) and adults (above one year) based on age. Overall morbidity and mortality due to digestive diseases were higher in 2018-19 (11.3\%, 1.6\%) as compared to 2019$20(8.2 \%, 0.7 \%)$. Morbidity was the highest in young ones followed by kids and adults whereas mortality was the highest in kids followed by young ones and adults. In rainy season, morbidity was the highest followed by summer and winter. However, mortality occurred mostly in summer followed by rainy and winter season. Both morbidity and mortality were more prominent in male goats than females. Morbidity and mortality in Ganjam goats reared in range system were higher as compared to those reared in semi-intensive system.
\end{abstract}

\section{HIGHLIGHTS}

( Rainy and Summer season had higher relative risk of morbidity and mortality of digestive diseases compared Winter season.

0 Kids and young age groups had higher risk of morbidity and mortality for digestive diseases.

(0 Semi-intensive system of management had lower risk of morbidity due to digestive diseases.

Keywords: Risk factors, odds ratio, digestive diseases, Morbidity, Mortality, relative risk

Goats play an important role in the food and nutritional security of the rural poor especially in the rain-fed regions where crop production is uncertain, and rearing large ruminants is restricted by acute scarcity of feed and fodder. Goat rearing has distinct economic and managerial advantages over other livestock because of its less initial investment, low input requirement, higher prolificacy, early sexual maturity, and ease in marketing. The landless agricultural labourers, marginal and small farmers in the country are mostly associated with goat rearing. Goat rearing, which is one of the most widely adopted

How to cite this article: Karna, D.K., Acharya, A.P., Das, B.C., Nayak, G. and Dibyadarshini, M.R. (2021). Relative Risk and Odds Ratio of Risk Factors Associated with Digestive Diseases in Ganjam Goats of Odisha. J. Anim. Res., 11(04): 661-667.

Source of Support: None; Conflict of Interest: None 
livestock activities in India, has the potential to emerge as a very good source of income and employment for the rural people especially in the less favoured environments. However, to harness this potential, the productivity and profitability of existing goat production systems need to be improved substantially. Shortage of feed in quantity and quality, poor management lead to high incidence of diseases, low productivity and poor reproduction (Mahmud et al., 2015). Among the wide range of diseases that affect goats, digestive diseases are one of the major diseases responsible for goat morbidity and mortality losses. The digestive system disorders in small ruminants cover a group of important diseases and are responsible for large economic losses. Digestive diseases of goat include non-infectious diseases like metabolic and nutritional deficiency diseases and infectious diseases like parasitic diseases and diseases caused due to pathogens like PPR, HS, FMD, enterotoxaemia, goat pox.The morbidity and mortality of goats affect the economic gain of the goat farmers through annual sale of goats. In India, few studies have been done on the incidence of digestive disorders in goats (Lira et al., 2013; Chaudhary and Singh, 2014; Upadhyay et al., 2015; Pawaiya et al., 2017). Morbidity and mortality rates in Ganjam goats due to different diseases have been reported by Karna et al. (2020b); but no reports are available regarding morbidity and mortality of Ganjam goat in field condition particularly due to digestive diseases. Considering the relative scarcity of studies on the epidemiology of digestive diseases in goats the objective of this work was to document the morbidity and mortality pattern of Ganjam goats due to diseases affecting the digestive system from April 2018 to March 2020 and determine possible risk factors for exposure to digestive diseases in Ganjam goats of Odisha under field condition.

\section{MATERIALS AND METHODS}

\section{Study area}

Four clusters such as Chhatrapur, Rambha, Khallikote and Jirabadi of the All India Coordinated Research Project on goat improvement operating in the Ganjam District in Odisha were selected for study. Ganjam district is located at $19.35^{\circ}-19.92^{\circ} \mathrm{N}$ and $84.98^{\circ}-85.12^{\circ} \mathrm{E}$. The temperature experienced in these areas ranges from $37^{\circ} \mathrm{C}$ to $39^{\circ} \mathrm{C}$ and $10.8^{\circ} \mathrm{C}$ to $11.5^{\circ} \mathrm{C}$, respectively and annual rainfall ranges from $1577 \mathrm{~mm}$ to $1597 \mathrm{~mm}$ (Karna et al. 2020a). Humidity is high throughout the year, average being $75 \%$. The research work was carried out in Ganjam district in the state of Odisha during April 2018 to March, 2020.

\section{Animals}

Total of 5845 Ganjam goats of 71 goat keepers belonging to twenty villages and 5205 Ganjam goats of 104 goat keepers belonging to twenty-six villages were observed for the study in 2018-19 and 2019-20, respectively. Morbidity and mortality data due to digestive diseases were collected on the basis of year, age, sex, season and rearing management from all the selected goat farmers of Chhatrapur, Rambha and Khallikote blocks of Ganjam district of Odisha for the period of two years from April 2018 to March 2020.

\section{Managemental practices}

Mostly two types of rearing system are practised by Golla farmers for rearing Ganjam goats i.e. Range system and Semi-intensive system. The goats reared under range system are not provided any supplementary feed as the goat farmers send these goats to distant jungles of 20-25 $\mathrm{km}$ away from home in search for browsing material. The flock size varies from 100 to 500. Ganjam goats usually rely on browsing poor quality herbs, shrubs, tree leaves, matured grass and dry fallen leaves in the range forest of native tract. Goats kept under semi-intensive condition are fed green pasture grasses, tree leaves, paddy straw with supplementation of concentrates.

\section{Herd health care}

Goats were vaccinated against HS, PPR, Goat pox and administered with anthelmintics. Control measures against diseases were undertaken with appropriate drugs/ measures.

\section{Experimental design}

Data on number of morbidity and mortality due to digestive disease were classified as per their respective year of disease, season, age and sex of animal and managemental practices. The season-wise morbidity and mortality was 
divided into three seasons, i.e., summer season (March to June), rainy season (July to October) and winter season (November to February). Age-wise morbidity and mortality was classified into different age groups viz., kids (0-3 months), young ones (3-12 months) and adults (above one year).

\section{STATISTICAL ANALYSIS}

Morbidity of digestive diseases was estimated as the ratio of the number goats falling sick due to digestive diseases to the total number of goats under risk for that period. Mortality in goats due to digestive diseases was estimated as the ratio of the goats dying due to digestive diseases to the total number of goats under risk for the period i.e. year and season. The association of risk factors viz. year and season of exposure, sex and age group categories of the animals and the types of management of goats with morbidity and mortality were analysed applying Chisquare test using $\mathrm{R}$ software (version 4.0.5). The logistic regression models were fitted for risk factors such as year of observation, season, sex, age group and rearing management of goats. Relative risks and odds ratio of morbidity and mortality in these goats was analysed using a univariate and multivariate logistic regression analysis model that was carried out in $\mathrm{R}$ software (version 4.0.5). The multivariate logistic regression model equation had $\mathrm{Y}$ as dependent variable. $\mathrm{Y}$ is the logarithm of odds of goats being affected with digestive diseases (morbidity) or death due to digestive diseases (mortality).

$$
\begin{aligned}
Y= & \log \left(\frac{P}{1-P}\right) \\
= & \beta_{0}+\beta_{1}(\text { Year })+\beta_{2}(\text { Season })+\beta_{3}(\text { Sex })+ \\
& \beta_{4}(\text { Age group })+\beta_{5}(\text { Management })
\end{aligned}
$$

where, $P=$ probability of Goats diseased /dead $(P(\mathrm{dead} /$ diseased $)=1$ ) due to digestive diseases. $\beta 0, \beta 1 \ldots \ldots, \beta 5$ : parameter values of regression coefficients of predictor variables. The graphs of the confidence interval of the odds ratio of the risk attributable to various factors are produced using the final fit package in $\mathrm{R}$ software (version 4.0.5). The odds ratio of morbidity and mortality taking only one risk factor (uni-variable) are presented in table 2 and table 4 respectively. The odds ratios of morbidity and mortality for various risk factors for digestive diseases simultaneously(multi-variable) along with the
95\% confidence interval are presented in Fig. 1 and 2 respectively.

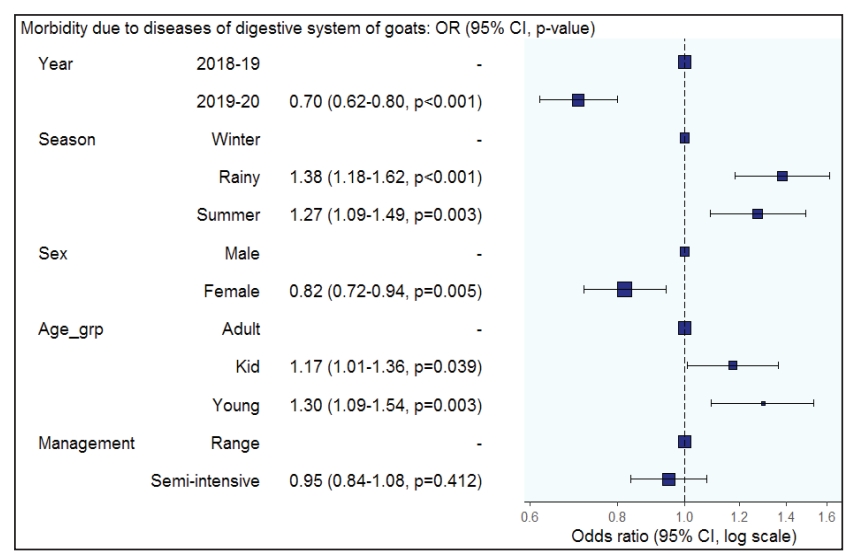

Fig. 1: Odds Ratio plot of risk factors for Morbidity of diseases of digestive system in Ganjam goats

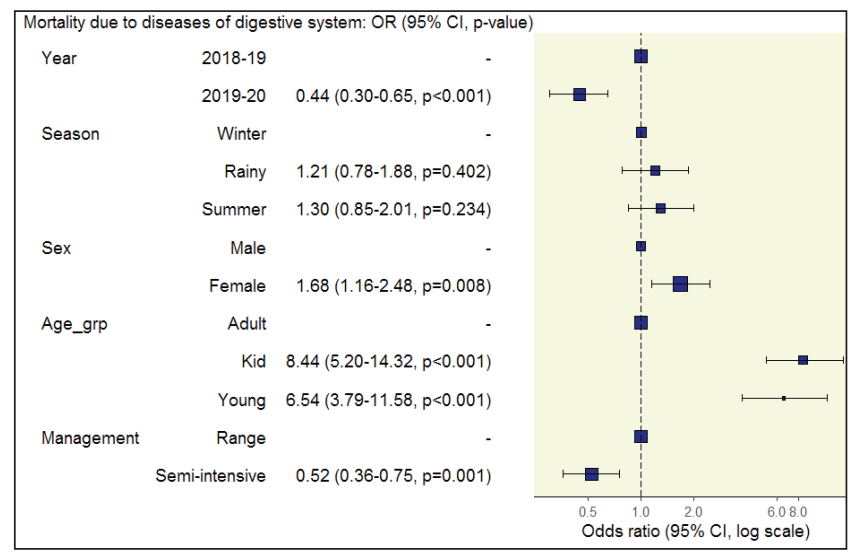

Fig. 2: Odds Ratio plot of risk factors for mortality due to diseases of digestive system in Ganjam goats

\section{RESULTS AND DISCUSSION}

\section{Morbidity pattern}

Morbidity pattern associated with digestive diseases in goats for the two-year observation period is presented in Table 1 . The average morbidity rate due to digestive diseases during the two-year observation period was found to be $9.85 \%$. In ascending year-wise order, the overall morbidity of goats due to digestive diseases decreased progressively with the highest morbidity of $11.3 \%$ (546/5845) occurring during 2018-19, which gradually 
Table 1: Morbidity pattern in Ganjam Goats for Digestive diseases

\begin{tabular}{llllll}
\hline Factors & Levels & Total & Diseased & $\mathbf{\%}$ & Relative Risk (95\% CI) \\
\hline Year & $2018-19$ & 5845 & 662 & 11.3 & Reference \\
& $2019-20$ & 5205 & 426 & 8.2 & $0.72(0.64-0.81)$ \\
\hline Season & Winter & 3876 & 317 & 8.2 & Reference \\
& Rainy & 3571 & 400 & 11.2 & $1.37(1.19-1.57)$ \\
& Summer & 3603 & 371 & 10.3 & $1.26(1.09-1.45)$ \\
\hline \multirow{2}{*}{ Sex } & Male & 3468 & 398 & 11.5 & Reference \\
& Female & 7582 & 690 & 9.1 & $0.79(0.70-0.89)$ \\
\hline \multirow{2}{*}{ Age group } & Adult & 6021 & 531 & 8.8 & Reference \\
& Kid & 3109 & 334 & 10.7 & $1.22(1.07-1.38)$ \\
& Young & 1920 & 223 & 11.6 & $1.31(1.14-1.53)$ \\
\hline Manage-ment & Range & 5526 & 562 & 10.2 & Reference \\
& Semi-intensive & 5524 & 526 & 9.5 & $0.93(0.83-1.04)$ \\
\hline
\end{tabular}

Table 2: Odds Ratio of risk factors due to Digestive Diseases of morbidity of Ganjam Goats

\begin{tabular}{llllll}
\hline Factors & Levels & Normal & Diseased & Odds Ratio (univariable, 95\% CI) & p-value \\
\hline Year & $2018-19$ & 5183 & 662 & Reference & - \\
& $2019-20$ & 4779 & 426 & $0.70(0.61-0.79)$ & $<0.001$ \\
\hline \multirow{2}{*}{ Season } & Winter & 3559 & 317 & Reference & - \\
& Rainy & 3171 & 400 & $1.42(1.21-1.65)$ & $<0.001$ \\
& Summer & 3232 & 371 & $1.29(1.10-1.51)$ & - \\
\hline \multirow{2}{*}{ Sex } & Male & 3070 & 398 & Reference & $<.002$ \\
\hline \multirow{2}{*}{ Age group } & Female & 6892 & 690 & $0.77(0.68-0.88)$ & - \\
& Adult & 5490 & 531 & Reference & $\mathrm{p}=0.001$ \\
& Kid & 2775 & 334 & $1.24(1.08-1.44)$ & $<0.001$ \\
\hline \multirow{2}{*}{ Manage-men } & Young & 1697 & 223 & $1.36(1.15-1.60)$ & - \\
& Range & 4964 & 562 & Reference & $\mathrm{p}=0.253$ \\
\hline
\end{tabular}

decreased to the lowest of $8.2 \%(238 / 5205)$ during 2019-2020. It was observed that the overall morbidity specifically due to digestive diseases during the two-year period were not equally distributed $(\mathrm{p}<0.001)$, and there was high association between years in consideration and morbidity occurred. Similar studies were also conducted by Lira et al. (2013), Chaudhary and Singh (2014) and Tifashe et al. (2017) where the overall morbidity due to digestive diseases were found to be $71.7 \%, 1.56 \%$ and $6.6 \%$, respectively. The analysis of morbidity rate revealed that it had significant $(\mathrm{p}<0.001)$ association with season. The incidence of digestive diseases was observed more in rainy season $(11.2 \%)$ followed by summer $(10.3 \%)$ and winter $(8.2 \%)$. Similar observations were also made by Dohare et al. (2013) in goats of Chambal division of Madhya Pradesh where morbidity due to diarrhoea causing digestive diseases was more in summer (50\%) and rainy $(40 \%)$ as compared to winter (12.2\%). However, results obtained from the study conducted by Tifashe et al. (2017) showed higher morbidity of goats in autumn (36\%) followed by $31.8 \%, 27.3 \%, 4.5 \%$ during spring, winter and summer, respectively. Sex-wise morbidity pattern in goat population during the study period of 201820 showed significant difference $(\mathrm{p}<0.001)$ between male and female goats suffering from digestive diseases. Similar observations were made by Chaudhary and Singh (2014) whereas study conducted by Tifashe et al. (2017) showed that morbidity due to digestive disease was higher 
in females $(10 \%)$ than in males $(8 \%)$. Age-wise analysis of morbidity in goats revealed that overall morbidity rate was highest in young ones $(11.6 \%)$ followed by kids $(10.7 \%)$ and adults $(8.8 \%)$. Morbidity percentages due to digestive diseases in different age groups differed significantly $(p<0.001)$. Similar observations were made by Chaudhary and Singh (2014) while Tifashe et al. (2017) found that kids had less morbidity than adults. Analysis based on rearing management revealed that goats depending on range system $(10.2 \%)$ for nutrition showed higher morbidity as compared to goats depending on semi-intensive system $(9.5 \%)$.

The logistic regression analysis with respect to digestive diseases showed significance $(p<0.001)$ between year, season, sex, and age (Table 2). Ganjam goats were at a lower risk of getting infected with digestive diseases in 2019-20 (OR=0.70) than in 2018-19. Season-wise, goats were at a higher risk of morbidity in acquiring digestive diseases in rainy season $(\mathrm{OR}=1.42)$ and summer season $(\mathrm{OR}=1.29)$ than in winter. Young stocks $(\mathrm{OR}=1.36)$ and kids $(\mathrm{OR}=1.24)$ were at higher risk of morbidity than adults. Female goats $(\mathrm{OR}=0.77)$ were at lower risk of morbidity than male. Similar results were also obtained by Chaudhary and Singh 2014 from the logistic regression analysis of morbidity due to digestive diseases with respect to age and sex. Ganjam goats reared in range system were at higher risk of morbidity than those reared in semiintensive system $(\mathrm{OR}=0.93)$ though it was statistically not significant.

\section{Mortality pattern}

Mortality of goats associated with digestive diseases from 2018-20 are presented in Table 3. The average mortality rate due to digestive diseases during the two-year observation period was found to be $1.18 \%$. A total of $94(1.6 \%)$ goats and $37(0.7 \%)$ goats died due to digestive diseases out of a population of total 5845 goats in 2018-19 and 5205 goats in 2019-20, respectively. Statistical analysis revealed that total mortality on account of digestive diseases were not equally distributed through the years, and there was significantly high association $(p<0.001)$ between the years in consideration and mortality of goats. The overall mortality of goats decreased progressively with the highest mortality occurring during 2018-19 (1.6\%), which gradually decreased during 2019-2020 (0.7\%).
The mortality due to digestive diseases was observed more in summer $(1.3 \%)$ and rainy season $(1.3 \%)$ than in winter $(1 \%)$. In season-wise analysis the association of mortality rate with season was found to be non-significant $(p<0.001)$. Sex-wise mortality pattern in goat population during the study period of 2018-20 revealed that mortality rate in male and female goats that died from digestive diseases were similar during the given time period. Agewise analysis showed that overall mortality was highest in kids $(2.4 \%)$ followed by young ones $(1.9 \%)$ and adults $(0.3 \%)$. It was observed that the kids $(0-3$ months $)$ were highly affected $(\mathrm{p}<0.001)$ with digestive diseases leading to death, whereas goats of young (6-12 months) and adult age groups were comparatively less affected $(\mathrm{p}<0.001)$. Thus, age was found to be an important factor contributing to the mortality due to digestive diseases. Analysis based on rearing management revealed that goats depending on range system $(1.6 \%)$ for nutrition were observed to show higher mortality as compared to goats depending on semiintensive system $(0.8 \%)$. Similar studies were conducted in goats by Pawaiya et al. (2017) for a period of 25 years where overall mortality due to alimentary diseases was $7.67 \%$ and significant differences could not be found for sex-wise and season-wise mortality patterns in goats. However, mortality in the kids ( $0-3$ months) and adult ( $>12$ months) were found to be equal and highly significant compared to young ones (3-6 months \& 6-12 months). Upadhyay et al. (2015) in his study over a period of 12 years found that overall mortality due to digestive diseases was $3.51 \%$ and highest mortality occurred in rainy season followed by winter and summer. Observations made by Chaudhary and Singh (2014) in their study showed overall mortality of $0.91 \%$ in goats due to digestive diseases.

The overall logistic regression analysis of mortality data revealed significant $(\mathrm{p}<0.001)$ difference between year, age groups and rearing management (Table 4). Ganjam goats were at a lower risk of mortality due to digestive diseases in 2019-20 $(\mathrm{OR}=0.44)$ than in 2018-19. The analysis showed that kids $(\mathrm{OR}=7.42)$ and young stocks $(\mathrm{OR}=5.73)$ were at higher risk of mortality than adults while there was no significant difference in mortality in male and female goats $(\mathrm{OR}=1.00)$. Season-wise, goats were at a higher risk of mortality due to digestive diseases in rainy season $(\mathrm{OR}=1.01)$ and summer season $(\mathrm{OR}=0.27)$ than in winter. The overall logistic regression analysis of mortality data based on rearing management revealed that goats reared 
Table 3: Mortality pattern in Ganjam Goats for Digestive Diseases

\begin{tabular}{llllll}
\hline Factors & Levels & Total & Dead & \% & Relative Risk (95\% CI) \\
\hline Year & $2018-19$ & 5845 & 94 & 1.6 & Reference \\
& $2019-20$ & 5205 & 37 & 0.7 & $0.44(0.30-0.64)$ \\
\hline Season & Winter & 3876 & 38 & 1.0 & Reference \\
& Rainy & 3571 & 45 & 1.3 & $1.28(0.84-1.97)$ \\
& Summer & 3603 & 48 & 1.3 & $1.36(0.89-2.07)$ \\
\hline Sex & Male & 3468 & 41 & 1.2 & Reference \\
& Female & 7582 & 90 & 1.2 & $1.00(0.69-1.45)$ \\
\hline \multirow{2}{*}{ Age group } & Adult & 6021 & 20 & 0.3 & Reference \\
& Kid & 3109 & 75 & 2.4 & $7.26(4.44-11.87)$ \\
& Young & 1920 & 36 & 1.9 & $5.64(3.28-9.72)$ \\
\hline Manage-ment & Range & 5526 & 87 & 1.6 & Reference \\
& Semi-intensive & 5524 & 44 & 0.8 & $0.50(0.35-0.73)$ \\
\hline
\end{tabular}

Table 4: Odds Ratio of risk factors due to Digestive Diseases of mortality of Ganjam Goats

\begin{tabular}{|c|c|c|c|c|c|}
\hline Factors & Levels & Normal & Dead & Odds Ratio (uni-variable, $95 \%$ CI) & p-value \\
\hline \multirow[t]{2}{*}{ Year } & 2018-19 & 5751 & 94 & Reference & \\
\hline & 2019-20 & 5168 & 37 & $0.44(0.30-0.64)$ & $<0.001$ \\
\hline \multirow[t]{3}{*}{ Season } & Winter & 3838 & 38 & Reference & \\
\hline & Rainy & 3526 & 45 & $1.29(0.84-2.00)$ & $\mathrm{p}=0.252$ \\
\hline & Summer & 3555 & 48 & $1.36(0.89-2.10)$ & $\mathrm{p}=0.155$ \\
\hline \multirow[t]{2}{*}{ Sex } & Male & 3427 & 41 & Reference & \\
\hline & Female & 7492 & 90 & $1.00(0.70-1.47)$ & $\mathrm{p}=0.983$ \\
\hline \multirow[t]{3}{*}{ Age group } & Adult & 6001 & 20 & Reference & \\
\hline & Kid & 3034 & 75 & $7.42(4.61-12.49)$ & $<0.001$ \\
\hline & Young & 1884 & 36 & $5.73(3.35-10.11)$ & $<0.001$ \\
\hline \multirow[t]{2}{*}{ Manage-ment } & Range & 5439 & 87 & Reference & \\
\hline & Semi-intensive & 5480 & 44 & $0.50(0.35-0.72)$ & $<0.001$ \\
\hline
\end{tabular}

in range system were at higher risk of mortality than those reared in semi-intensive system $(\mathrm{OR}=0.77)$. The logistic regression analysis done by Chaudhary and Singh (2014) showed that kids and young stocks were at higher risk of mortality due to digestive diseases than adults and males were at higher risk of mortality than females.

\section{CONCLUSION}

This study confirms that overall morbidity and mortality rate due to digestive diseases averaged $9.85 \%$ and $1.18 \%$, respectively during the two-year observation period. Morbidity and mortality observed were higher in 201819 as compared to 2019-20. Morbidity rates were higher in rainy season followed by summer and winter whereas mortality mostly occurred in summer followed by rainy season and winter. Young ones showed higher morbidity followed by kids and adults whereas mortality was higher in kids than in young ones and adults. Males had significantly higher morbidity as compared to females whereas mortality pattern was similar in both sexes. After adjusting for all other risk factors the odds of mortality in females were 68 percent higher than that of males. Goats reared in range system were at a higher risk of acquiring digestive diseases as compared to those reared in semiintensive system. After adjusting for all the risk factors, the odds of mortality was almost half that of the range system. The year and season were significantly associated with 
the morbidity of goats due to digestive diseases whereas mortality showed significant association with year and age group. Rainy and Summer season posed higher risk for morbidity and mortality of digestive diseases as compared to the Winter season. Kids and young age groups had 7.2 and 5.6 times the risk of mortality due to digestive diseases observed for the adults.

\section{ACKNOWLEDGEMENTS}

Authors are thankful to All India Coordinated Research Project on goat improvement, (ICAR, New Delhi) for providing financial support to carry out this research.

\section{REFERENCES}

Chaudhary, J.K. and Singh, B. 2014. Morbidity and mortality rates in small ruminants in Himachal Pradesh, India. Indian J. Anim. Res., 48(6): 609-614.

Dohare, A.K., Singh, B., Bangar, Y., Prasad, S., Kumar, D., Shakya, G. 2013. Influence of age, sex and season on morbidity and mortality pattern in goats under village conditions of Madhya Pradesh. Vet. World, 6(6): 329-331.

Karna, D.K., Acharya, A.P., Das, B.C., Nayak, G.D. and Dibyadarshini, M.R. 2020a. Morphometry of Ganjam goats of Odisha and age specific body weight prediction from linear body measurements. Pharma Innov. J., SP-9(4): 171-175.
Karna, D.K., Acharya, A.P., Das, B.C., Nayak, G.D. and Dibyadarshini, M.R. 2020b. Morbidity and mortality rates of Ganjam goats of Odisha in field condition. J. Entomol. Zool. Stud., 8(5): 565-568.

Lira, M.A.A., Simões, S.V.D., Riet-Correa, F., Pessoa, C.M.R., Dantas, A.F.M. and Miranda Neto, E.G. 2013. Diseases of the digestive system of goats and sheep in the semi-arid region of Brazil. Pesq. Vet. Bras., 33: 193-198.

Mahmud, M.A.A., Rahman, M.M., Syem, M.A., Uddin, M.N., Mehraj, H. and Jamal Uddin, A.F.M. 2015. Study on morbidity and mortality rate and their probable causes of Black Bengal goats at Sador Upazila of Sirajganj, Bangladesh. Int. J. Bus. Soc. Sci. Res., 3(2): 116-119.

Pawaiya, R.V.S., Singh, D.D., Gangwar, N.K., Gururaj, K., Kumar, V., Paul, S., Sharma, N., Mishra, A.K., Kumar, A., Sharma, D.K. and Singh, S.V. 2017. Retrospective study on mortality of goats due to alimentary system diseases in an organized farm. Small Rum. Res., 149: 141-146.

Tifashe, M., Hassan, A., Herago, T. and Tesfamariam, G. 2017. Analysis of Morbidity and Mortality of Sheep and Goat in Wolaita Soddo Zuria District, Southern Ethiopia. Global Veterinaria, 18(3): 168-177.

Upadhyay, D., Patel, B.H.M., Sahu, S., Gaur, G.K. and Singh, M. 2015. Factors affecting survivability of local Rohilkhand goats under organized farm. Vet. World, 8(10): 1215-1218. 
